www.jmscr.igmpublication.org

Index Copernicus Value: 79.54

ISSN (e)-2347-176x ISSN (p) 2455-0450

crossref DOI: https://dx.doi.org/10.18535/jmscr/v7i5.140

\title{
In Vitro Evaluation of Antibacterial Efficacy of Nisin Calcium Hydroxide and Triple Antibiotic Paste in Three Different Vehicle
}

\author{
Authors \\ Dr Supratim Tripathi ${ }^{1}$, Dr Pallavi Mittal ${ }^{2 *}$, Dr Sharmistha Deb ${ }^{3}$, Dr Sheetal Verma ${ }^{4}$ \\ ${ }^{1}$ Reader, Department of Conservative Dentistry and Endodontics, Career Post Graduate Institute of Dental \\ ${ }^{2,3}$ PG Final Year Student, Department of Conservative Dentistry and Endodontics, Career Post Graduate \\ Institute of Dental Sciences and Hospital, Lucknow \\ ${ }^{4}$ Assistant Professor, Department of Microbiology, King George's Medical University, Lucknow \\ *Corresponding Author \\ Dr Pallavi Mittal
}

PG Final Year Student, Department of Conservative Dentistry and Endodontics, Career Post Graduate Institute of Dental Sciences and Hospital, Lucknow, UP, India

\begin{abstract}
Enterococcus Faecalis is the most common facultative anaerobic bacteria isolated from both secondary and persistent root canal infections. E. faecalis invades and adheres to the dentinal tubules with a depth of penetration ranging from 500 to $1000 \mu \mathrm{m}$, and has the ability to survive in harsh environmental conditions due to its potential to transform into the viable but noncultivable (VBNC) state. This Paper highlights the use of Nisin, Calcium Hydroxide and Triple Antibiotic Paste each as an intracanal medicaments combined with propylene glycol, CHX and saline used as a vehicle. Nisin, a chemical commonly used as a food preservative (meat and dairy products), is recently recommended for use as an intracanal medicament. Discovered in 1928, it is a naturally occurring antimicrobial cationic peptide, produced by Streptococcus lactis subspecies lactis. Propylene glycol which was suggested by Laws in 1962 has been evaluated for its possible use as a vehicle in the field of endodontics. It permits the release of calcium and hydroxyl ions essential for the therapeutic action. It has been found to be antibacterial, nonirritating to the periapical tissue. 2\% CHX is effective in completely eliminating E. Faecalis from the dentinal tubules up to a period of 15 days attributed to its substantive antimicrobial activity. This study aims to see the combined effect of Nisin, Calcium Hydroxide and Triple Antibiotic Paste when mixed with different vehicle.
\end{abstract}

\section{Introduction}

Bacteria remaining within the root canal are a significant factor in endodontic failures. Hence retreatment of endodontically treated teeth is a major challenge to clinicians. Enterococcus Faecalis is the most common facultative anaerobic bacteria isolated from both secondary and persistant root canal infections. ${ }^{[2]}$ Therefore for the achievement of sterilization and healing of infected root dentin the use of antimicrobial medicaments in combination with mechanical cleansing enhances the success of treatment.

Calcium Hydroxide, commonly used as an intracanal medicament has an effective antibacterial action against most endodontic microflora. But E. faecalis is resistant to the 
antimicrobial activity of $\mathrm{Ca}(\mathrm{OH})_{2}$ due to its PPI action and its potential to withstand high alkalinity. Studies have demonstrated that $2 \%$ Nisin, a chemical commonly used as a food preservative (meat and dairy products) is recently recommended for use as an intracanal medicament. Chemically, it is a polycyclic antimicrobial peptide with 34 amino acid residues which include uncommon amino acids, such as Ianthionine, methylanthionine, didehydro and didehydroaminobutyric acid. It has an antimicrobial activity against a wide range of gram positive bacteria and their spores, even against drug resistant E. faecalis isolates. ${ }^{[2]}$ Triple Antibiotic paste a combination of ciprofloxacin, metronidazole and minocycline has been suggested for root canal disinfection as it contains polymicrobial infections consisting of both aerobic and anaerobic bacteria species which may not be effective when single antibiotics are used.

To facilitate its application in the field of endodontics, it is generally mixed with vehicles. The type of vehicle used has a direct relationship with the concentration and velocity of ionic liberation as well as with the antibacterial action when the paste is carried in to the contaminated area. $^{[4]}$

Recently, a newly introduced vehicle, Propylene Glycol, has been evaluated for its possible use as a vehicle in the field of endodontics. It permits the release of calcium and hydroxyl ions essential for the therapeutic action. It has been found to be antibacterial, non irritating to the periapical tissue. $^{[3]}$

Chlorhexidine (CHX) has been widely used in Endodontics. It has an antibacterial activity against Gram positive and Gram negative microorganisms. ${ }^{[1]}$ It can be used as a vehicle because of its substantivity property, its adsorption capacity and slow liberation of active molecules by dental tissue. Chlorhexidine is effective in completely eliminating E. faecalis from the dentinal tubules upto a period of 15 days, attributed to its substantive antimicrobial activity.
Saline is a neutral vehicle with no antimicrobial property, only aids in easy placement of medicaments.

The Gold standard that has been documented till date for E. faecalis is Calcium Hydroxide + Chlorhexidine combination. Keeping in mind the biocompatibility issues this study aims to the use of three different antimicrobial agents, Nisin, Chlorhexidine and Triple Antibiotic paste which strongly condom the propogation of E.faecalis in association of three different vehicle, Propylene Glycol, Chlorhexidine and saline with increased substantivity and sustained release of the medicaments.

\section{Aim and Objectives}

The aim of the study is to evaluate the antibacterial efficacy of Nisin, Calcium Hydroxide \& Triple Antibiotic Paste in three different vehicles, Chlorhexidine, Propylene Glycol and Saline. Chlorhexidine + Calcium Hydroxide being the positive control.

\section{Materials and Methods}

The study will be conducted in the Department of Conservative Dentistry and Endodontics, Career Post Graduate Institute of Dental Sciences and Hospital, Lucknow.

One hundred and eighty extracted fully mature human permanent maxillary central incisors teeth with single canal were included in this study. They were cleaned and debrided for the removal of calculus. After debridement, teeth will be stored in $0.1 \%$ thymol solution until use.

Samples were decoronated upto length of $7 \mathrm{~mm}$. The working length determination was done by $10 \mathrm{~K}$ file until it was just visible at the apical foramen and keeping it short by $1 \mathrm{~mm}$. Chemomechanical debridement of root canal was done for all samples. Prepared samples will be divided into two groups comprising of eight experimental group and one control group. Experimental groups were further subdivided in to following groups: 


\begin{tabular}{|l|l|}
\hline Experimental Subgroups & Medicaments \\
\hline Subgroup A & Calcium Hydroxide + Propylene Glycol \\
\hline Subgroup B & Calcium Hydroxide + Saline \\
\hline Subgroup C & Triple Antibiotic Paste + Propylene Glycol \\
\hline Subgroup D & Triple Antibiotic Paste + Chlorhexidine \\
\hline Subgroup E & Triple Antibiotic Paste + Saline \\
\hline Subgroup F & Nisin + Propylene Glycol \\
\hline Subgroup G & Nisin + Chlorhexidine \\
\hline Subgroup H & Nisin + Saline \\
\hline
\end{tabular}

\begin{tabular}{|l|l|}
\hline Positive Control group & Medicament \\
\hline Subgroup I & Calcium Hydroxide + Chlorhexidine \\
\hline
\end{tabular}

All the prepared samples were sterilized and incubated. Bacterial lysis was done in Blood sheep agar broth. The reaction to the medicaments was done for a time period of $24 \mathrm{hrs}, 48 \mathrm{hrs}, 72 \mathrm{hrs}$ and 168 hrs. After every time slot the extent of lysis has administered and the readings were subjected to statistical analysis.

\begin{tabular}{|l|c|c|c|c|c|c|c|c|c|c|c|c|c|c|}
\hline & $\begin{array}{c}24 \\
\text { Hrs }\end{array}$ & $\begin{array}{c}48 \\
\text { hrs }\end{array}$ & $\begin{array}{c}72 \\
\text { hrs }\end{array}$ & $\begin{array}{c}1 \\
\text { week }\end{array}$ & $\begin{array}{c}24 \\
\text { hrs }\end{array}$ & $\begin{array}{c}48 \\
\text { hrs }\end{array}$ & $\begin{array}{c}72 \\
\text { hrs }\end{array}$ & $\begin{array}{c}1 \\
\text { week }\end{array}$ & $\begin{array}{c}24 \\
\text { hrs }\end{array}$ & $\begin{array}{c}48 \\
\text { hrs }\end{array}$ & $\begin{array}{c}72 \\
\text { hrs }\end{array}$ & $\begin{array}{c}1 \\
\text { week }\end{array}$ \\
\hline NISIN+PG (A1) & 22 & 25 & 30 & 30 & A2 & 20 & 22 & 25 & 26 & A3 & 20 & 20 & 25 & 25 \\
\hline TAP + CHX (B1) & 20 & 18 & 18 & 18 & B2 & 18 & 18 & 18 & 18 & B3 & 18 & 20 & 20 & 20 \\
\hline NISIN+ SALINE (C1) & 15 & 16 & 20 & 20 & C2 & 15 & 16 & 20 & 20 & C3 & 15 & 16 & 20 & 20 \\
\hline CA(OH)2 + PG (D1) & 19 & 19 & 19 & 19 & D2 & 18 & 19 & 19 & 19 & D3 & 19 & 19 & 19 & 19 \\
\hline CA(OH)2 + CHX (E1) & 20 & 20 & 22 & 22 & E2 & 20 & 20 & 25 & 25 & E3 & 20 & 20 & 25 & 25 \\
\hline CA(OH)2 + SALINE (F1) & 20 & 22 & 25 & 25 & F2 & 22 & 25 & 22 & 22 & F3 & 25 & 25 & 25 & 25 \\
\hline NISIN + CHX (G1) & 18 & 18 & 18 & 18 & G2 & 21 & 22 & 22 & 22 & G3 & 20 & 22 & 22 & 22 \\
\hline TAP + PG (H1) & 25 & 25 & 25 & 25 & H2 & 21 & 23 & 22 & 22 & H3 & 20 & 22 & 22 & 22 \\
\hline TAP + SALINE (I1) & 18 & 18 & 20 & 20 & I2 & 18 & 20 & 22 & 22 & I3 & 15 & 15 & 22 & 22 \\
\hline
\end{tabular}
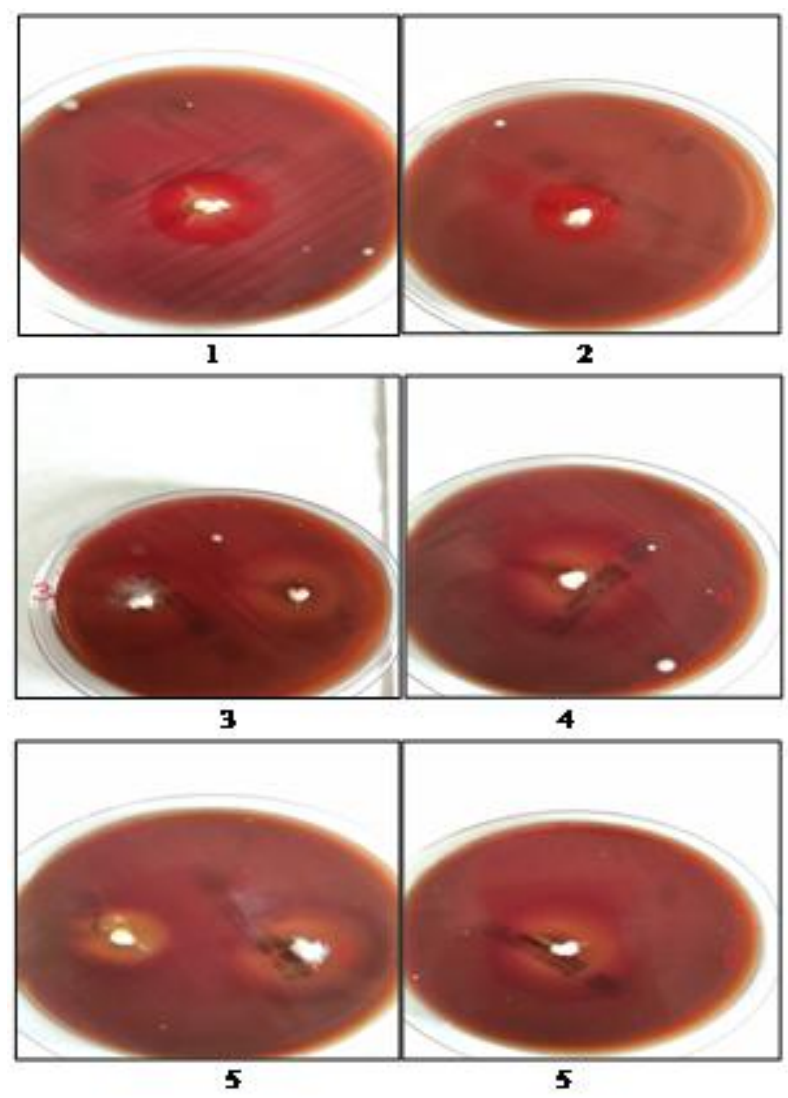

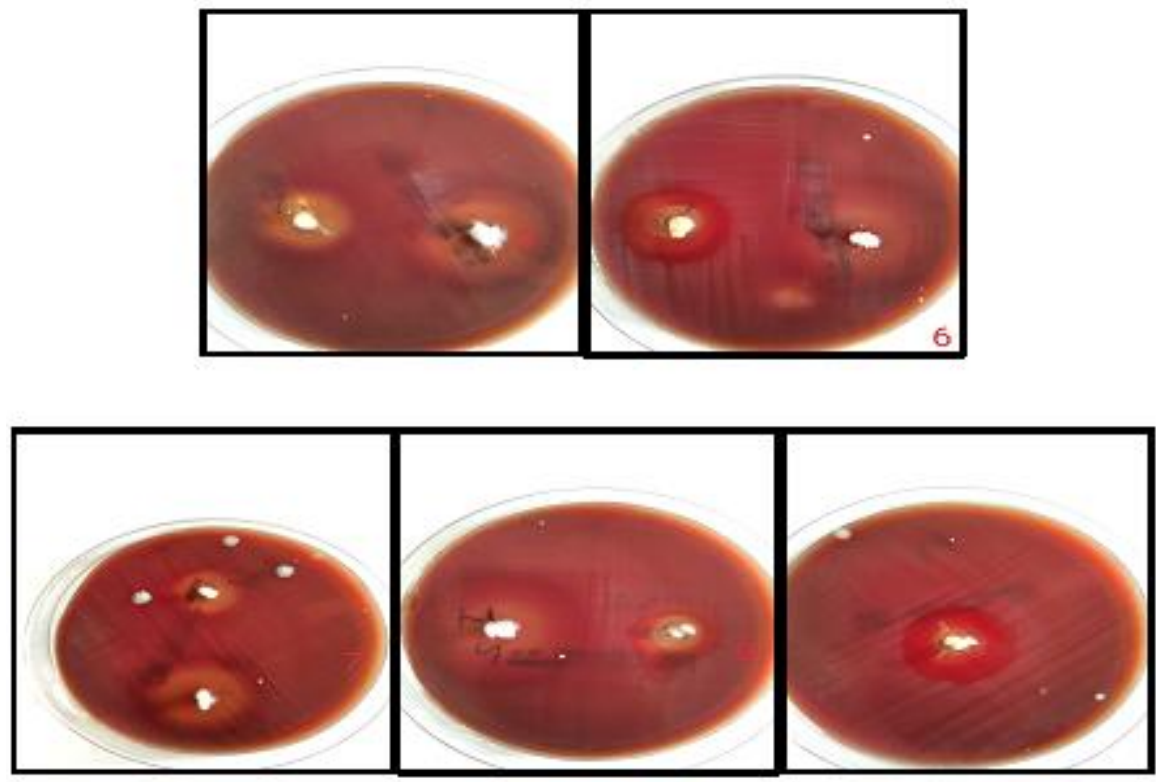

After 1 Week Inhibitory Zones of Different Group 1-NISIN + PG, 2- TAP + CHX, 3- NISIN + SALINE, 4- Ca(OH)2 + PG, 5-Ca(OH)2 + CHX, 6-Ca(OH)2 + SALINE, 7- NISIN + CHX, 8- TAP+ PG, 9- TAP+ SALINE.

\section{Results}

Statistical software IBM SPSS statistics 20.0 was used for the analysis of the data and Microsoft word and Excel were used to generate graphs, tables.etc. Statistical analysis was done using Kruskal-Wallis Test and Shapiro Wilk's test. There was statistically significant difference when the probability value was $\mathrm{p}<0.05$.

\section{Agar Well Diffusion Assay}

The antibacterial efficacy was detected by the formation of the zone of inhibition around the wells inoculated with the experimental groups. All the groups I, II, III, IV,V,VI,VII,VIII,IX showed inhibitory zones. The maximum diameter of 30 mm (1week) was obtained with Nisin when used with propylene glycol as a vehicle. The inhibitory zones of nisin at $24 \mathrm{hrs}(22 \mathrm{~mm}), 48 \mathrm{hrs}(25 \mathrm{~mm})$, and $72 \mathrm{hrs}(25 \mathrm{~mm})$ were comparable to the positive control.

Table 1: Intra group \& Intergroup Comparisons

\begin{tabular}{|c|c|c|c|c|c|c|c|}
\hline \multirow{2}{*}{\multicolumn{2}{|c|}{ Material }} & \multirow{3}{*}{$\begin{array}{l}24 \mathrm{hrs} \\
20.70\end{array}$} & \multirow{3}{*}{$\begin{array}{l}48 \mathrm{hrs} \\
22.45\end{array}$} & \multirow{3}{*}{$\begin{array}{l}72 \mathrm{hrs} \\
26.75\end{array}$} & \multirow{2}{*}{1 week } & \multicolumn{2}{|c|}{ Friedman Test } \\
\hline & & & & & & chi sa & n-value \\
\hline \multirow{2}{*}{ NISIN+PG } & Mean & & & & 27.10 & \multirow{2}{*}{57.10} & \multirow{2}{*}{$<0.001$} \\
\hline & SD & 0.98 & 2.09 & 2.45 & 2.22 & & \\
\hline \multirow{2}{*}{$\mathrm{TAP}+\mathrm{CHX}$} & Mean & 18.60 & 18.70 & 18.70 & 18.70 & \multirow{2}{*}{0.230} & \multirow{2}{*}{0.972} \\
\hline & SD & 0.94 & 0.98 & 0.98 & 0.98 & & \\
\hline \multirow{2}{*}{$\begin{array}{l}\text { NISIN+ } \\
\text { SALINE }\end{array}$} & Mean & 15.00 & 16.00 & 20.00 & 20.00 & \multirow{2}{*}{60.00} & \multirow{2}{*}{$<0.001$} \\
\hline & SD & 0.00 & 0.00 & 0.00 & 0.00 & & \\
\hline \multirow{2}{*}{$\begin{array}{l}\mathrm{CA}(\mathrm{OH}) 2+ \\
\mathrm{PG}\end{array}$} & Mean & 18.65 & 19.00 & 19.00 & 19.00 & \multirow{2}{*}{21.00} & \multirow{2}{*}{$<0.001$} \\
\hline & SD & 0.49 & 0.00 & 0.00 & 0.00 & & \\
\hline \multirow{2}{*}{$\begin{array}{l}\mathrm{CA}(\mathrm{OH}) 2 \\
\mathrm{CHX}\end{array}$} & Mean & 20.00 & 20.00 & 24.10 & 24.10 & \multirow{2}{*}{60.00} & \multirow{2}{*}{$<0.001$} \\
\hline & SD & 0.00 & 0.00 & 1.41 & 1.41 & & \\
\hline $\mathrm{CA}(\mathrm{OH}) 2$ & Mean & 22.45 & 24.10 & 23.95 & 23.95 & 14.06 & 0.003 \\
\hline
\end{tabular}




\begin{tabular}{|l|l|l|l|l|l|l|l|} 
SALINE & SD & 2.09 & 1.41 & 1.47 & 1.47 & & \\
\hline \multirow{2}{*}{ NISIN + CHX } & Mean & 19.65 & 20.60 & 20.60 & 20.60 & \multirow{2}{*}{39.00} & $<0.001$ \\
\cline { 2 - 9 } & SD & 1.31 & 1.96 & 1.96 & 1.96 & & \\
\hline \multirow{2}{*}{ TAP + PG } & Mean & 22.05 & 23.35 & 23.05 & 23.05 & \multirow{2}{*}{35.06} & $<0.001$ \\
\cline { 2 - 9 } & SD & 2.26 & 1.31 & 1.47 & 1.47 & & \\
\hline \multirow{2}{*}{$\begin{array}{l}\text { TAP } \\
\text { SALINE }\end{array}$} & Mean & 17.10 & 17.80 & 21.30 & 21.30 & \multirow{2}{*}{58.37} & $<0.001$ \\
\cline { 2 - 9 } & SD & 1.41 & 2.07 & 0.98 & 0.98 & & \\
\hline $\begin{array}{l}\text { Kruskal } \\
\text { Wallis Test }\end{array}$ & Chi-Sq. & 140.79 & 139.55 & 143.58 & 145.58 & & \\
\cline { 2 - 7 } & p-value & $<0.001$ & $<0.001$ & $<0.001$ & $<0.001$ & & \\
\hline
\end{tabular}

The Kruskal Wallis test of intergroup comparison shows significant differences among various groups at $24 \mathrm{hrs}, 48 \mathrm{hrs}, 72 \mathrm{hrs}$ and 1 week ( $\mathrm{p}<0.001$ for each). At 1 week the maximum mean score was $27.10 \pm 2.22$ seen for the NISIN+PG while minimum $18.70 \pm 0.98$ for the $\mathrm{TAP}+\mathrm{CHX}$. comparison revealed that with time maximum

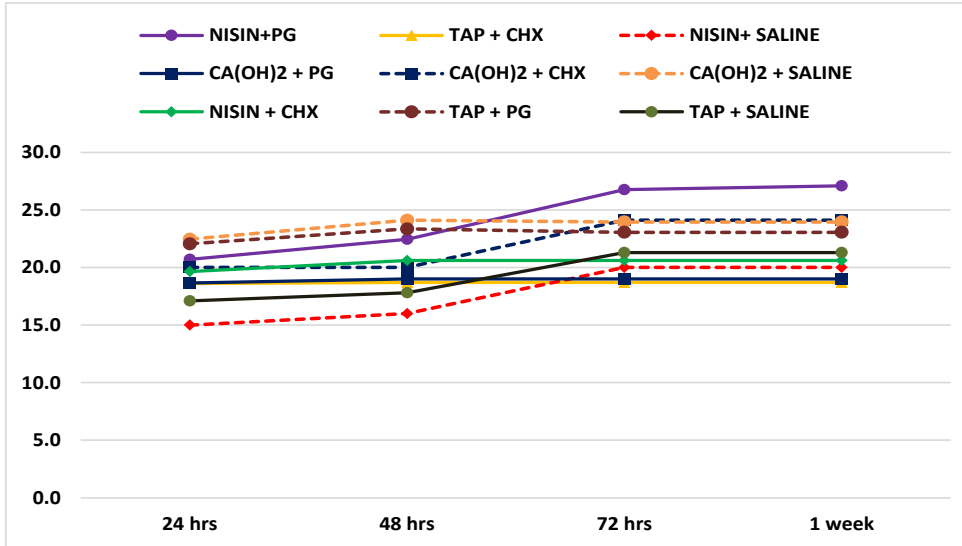

The Line Graph: Intergroup comparison [Graph 1]

\section{Discussion}

E. faecalis is among the most antibiotic-resistant bacteria known at present. E. faecalis has the ability to quickly acquire and disseminate antibiotic resistance genes by pheromone signals produced within the genus and species as well as by other bacterial genera. ${ }^{[14]}$ The primary aim of endodontic treatment is to minimize the surgical intervention and maintain health and function of infected teeth by biomechanical preparation of the root canal (cleaning, shaping and disinfection) and to hermetically seal it with no discomfort to the patient, and provide conditions for the periradicular tissues to heal. In the current study, Nisin exhibited superior antimicrobial activity changes occurred in NISIN+Saline and $\mathrm{Ca}(\mathrm{OH})_{2}+\mathrm{CHX}$ (chi sq=60.0, $\mathrm{p}<0.001$ ) which just followed by TAP+Saline (chi $\mathrm{sq}=58.37, \mathrm{p}<0.001$ ) and NISIN+PG (chi sq=57.10, $\mathrm{p}<0.001$ ) while no significant change with time was found in $\mathrm{TAP}+\mathrm{CHX}$ (chi $\mathrm{sq}=0.230, \mathrm{p}=0.972$ ) compared with $\mathrm{Ca}(\mathrm{OH})_{2}$ and TAP when used along with Propylene Glycol as a vehicle. This is because the antimicrobial mechanism of Nisin is independent of the $\mathrm{pH}$ of the surrounding tissues. This provides a means to eradicate $\mathrm{E}$. faecalis by a method to which it has no defense mechanism. Experiments conducted by Severina et al proved that nisin is less toxic, odorless, colorless, tasteless, and has low drug resistance rates compared with other similar antimicrobial peptides. ${ }^{[2]}$ Nisin exhibits its antibacterial effect by the following mechanisms: According to Jack et al, it acts by inserting into the bacterial plasma membrane and triggering the activity of bacterial murein hydrolases, resulting in damage or 
degradation of the peptidoglycans and lysis of cells. Du Plessis et al. ${ }^{[2]}$ reported that it is due to interaction with the phospholipid membrane of the target bacterial cell causing autolysis and irreparable damage to plasma membrane. Crandal et al showed that it disrupts the cellular mechanism, inducing leakage of small intracellular contents from the cell.

Tong et al. ${ }^{[14]}$ showed by adding Nisin to MTAD (mixture of Doxycycline, citric acid and detergent) shows increased effectiveness against E. Faecalis biofilm. Nisin exerts its antibacterial action by disrupting cell wall synthesis, forms pores in cell membrane and causes rapid reflux of essential cytoplasmic small molecules.

The successful use of $\mathrm{Ca}(\mathrm{OH}) 2$ paste as a root canal dressing is related to its dissociation into two ions, $\mathrm{Ca}^{+}$and Hydroxyl ions in which hydroxyl ion is responsible for alkalizing the environment. The high $\mathrm{PH}$ of $\mathrm{Ca}(\mathrm{OH})_{2}$ attenuate the inflammatory process, and its release of hydroxyl ions makes it an excellent antibacterial agent. ${ }^{[37]}$ Lage-Marques et al. ${ }^{[28]}$ concluded that calcium hydroxide pastes in aqueous and viscous vehicles are more effective than those in oily vehicles because the former reach higher $\mathrm{pH}$ levels more quickly and remain stable for a longer period of time. Other authors have also reported $^{[21]}$ the greater effectiveness of aqueous and viscous vehicles.Similarly to previous reports, this study evidenced that saline- and propylene glycol-containing pastes diffuse well through dentin, as can be seen in Tables 1,2 and

The concern of the antibiotic paste is that it may cause bacterial resistance. TAP was proved to be biocompatible and contains both bactericidal (metronidazole, ciprofloxacin) and bacteriostatic (minocycline) agents to allow for successful revascularization. Metronidazole is a nitroimidazole compound that exhibits a broad spectrum of activity against protozoa and anaerobic bacteria. Minocycline is a semisynthetic derivative of tetracycline with a similar spectrum of activity. Ciprofloxacin, a synthetic fluoroquinolone, has a bactericidal mode of action. Metronidazole and ciprofloxacin can generate fibroblasts. TAP can help promote functional development of the pulp-dentin complex. $^{[25]}$

The delivery of calcium hydroxide powder is alone is difficult or impossible so it must be mixed with a liquid to facilitate its placement within the canal. Calcium hydroxide when mixed with vehicles has shown the potential to release calcium and hydroxyl ions through cementum. The rate of dissociation into ions and diffusion through dentinal tubules is determined by the vehicles used. Thus, vehicles play an important role in the ionic dissociation.

Propylene glycol (1,2-propanediol), is a dihydric alcohol. It was suggested by Laws in 1962 for its possible use as a vehicle in endodontics. Propylene glycol is a colorless liquid with mild acrid smell and sweet taste. Olitzky (1965) stated that concentrated solution of propylene glycol showed marked germicidal efficiency. Hence, it can be used as a vehicle as it has the potential for preventing and treating microbial infections. Bhat and Walkevar, Thomas et al. ${ }^{[39,40]}$ stated that as compared to other commonly used vehicles for intracanal medicaments propylene glycol has been found to be less cytotoxic and also possess antibacterial properties that are highly beneficial in the endodontic treatment. Fava and Saunders said that propylene glycol possesses hygroscopic properties which allow absorption of water. This resulted in a sustained release of the intracanal medicament for prolonged period of time. ${ }^{[41]}$

Chlorhexidine has been used extensively in endodontics for irrigation and as an intracanal medicament and is considered as the gold standard. ${ }^{[5]}$ It is a cationic biguanide and an antiseptic which has substantive properties and even at higher concentrations has very low toxicity. At low concentration, it is bacteriostatic, whereas at high concentration, it is bactericidal and shows antimicrobial activity from concentrations as low as $0.1 \%$; and shows bactericidal activity at $2 \%$ and is biocompatible. The MIC of chlorhexidine started from $0.019 \%$ 
against $P$. gingivalis to $0.078 \%$ against other facultative anaerobes with the highest concentration against $E$. faecalis, i.e., $0.156 \%$.

All the above selected vehicles do possess antimicrobial activity along with different intracanal medicaments. No significant difference with time was found in TAP + CHX, whereas Nisin + PG shows maximum mean score at 1 week as compared to other groups.

The agar well diffusion method or well plate method or the agar diffusion method was used in this study as it is the most commonly used method of antimicrobial activity determination especially of newer substances like plant extracts, new drug formulations, etc. This technique is a wellaccepted way of comparing the antibacterial effect of different dental materials, medicaments, etc. ${ }^{[45]}$ Agar well diffusion was used for the combination of antimicrobial drugs with vehicles as though E-test being the latest method, it is not feasible for combination of drugs.

\section{Conclusion}

Within the limits of this invitro study, it can be concluded that Nisin was effective at eradicating $E$. faecalis cells in pure culture and was comparable with calcium hydroxide, triple antibiotic paste in elimination of $E$. faecalis from within the root canal system when used with propylene glycol, chlorhexidine and saline as a vehicle.

\section{Clinical Significance}

Nisin, when used as an intracanal medicament, is effective in eliminating E. faecalis when compared with the combination of $\mathrm{Ca}(\mathrm{OH})_{2}$ and Triple Antibiotic Paste.

\section{References}

1. Bilgi PS, Shah NC, Mehta J. COMPERATIVE Evaluation Of Mixture Of Calcium Hydroxide and Chlorhexidine, with Triple Antibiotic Paste and Combination Of Calcium Hydroxide, Chlorhexidine, and Lycopene on Incidence of Interappointment Flare-up: An in vivo Study. Int J Clin Dent Res 2017;1(1):1014.

2. Mitthra S, Abraham TA, Subbiya A et al. Antibacterial Efficacy of Nisin and Calcium Hydroxide with a Proton Pump Inhibitor as an Intracanal Medicament. World J Dent 2018;9(2):111-1.

3. Sirén EK, Haapasalo MP, Waltimo TM, Ørstavik D. In vitro antibacterial effect of calcium hydroxide combined with chlorhexidine or iodine potassium iodide on Enterococcus faecalis. Eur J Oral Sci 2004 Aug;112(4):326-331.

4. G. H. Robert, F. R. Liewehr, T. B. Buxton, and J. C. McPherson III, "Apical diffusion of calcium hydroxide in an in vitro model," Journal of Endodontics,2005; 31(1): 57-60.

5. Gomes BP, Vianna ME, Sena TN, Zaia AA, Ferraz CC, Filho FJS. In vitro evaluation of the antimicrobial activity of calcium hydroxide combined with chlorhexidine gel used as intracanal medicament. Oral Surg Oral Med Oral Pathol Oral Radiol Endod. 2006 Oct;102(4):544-550.

6. I. C. Gomes Camoes, M. R. Salles, and O. Chevitarese, " $\mathrm{Ca} \sim 2+$ diffusion through dentin of $\mathrm{Ca}(\mathrm{OH}) 2$ associated with seven different vehicles," Journal of Endodontics, 2003; 29(12): 822-825.

7. Wagner C, Barth VC Jr, de Oliveira SD, Campos MM. Effectiveness of the proton pump inhibitor omeprazole associated with calcium hydroxide as intracanal medication: an in vivo study. J Endod 2011 Sep;37(9):1253-1257.

8. Bhat KS, Walvekar SV. Evalution of bactericidal property of propylene glycol for its possible use in endodontics. Arogya J Health Sci. 1975;1:54-9.

9. Ferreira FB, Torres SA, Rosa OP, Ferreira CM, Garcia RB, Marcucci MC, et al. Antimicrobial effect of propolis and 
other substances against selected endodontic pathogens. Oral Surg Oral Med Oral Pathol Oral Radiol Endod 2007;104:709-16.

10. Turner SR, Love RM, Lyons KM. An invitro investigation of the antibacterial effect of nisin in root canals and canal wall radicular dentine. Int Endod $\mathrm{J}$ 2004;37:664-71

11. Mistry KS, Sanghvi Z, Parmar G, Shah S. The antimicrobial activity of Azadirachta indica, Mimusops elengi, Tinospora cardifolia, Ocimum sanctum and $2 \%$ chlorhexidine gluconate on common endodontic pathogens: An in vitro study. Eur J Dent. 2014;8:172-7

12. Hoshino E, Kurihara-Ando N, Sato I, Uematsu H, Sato M, Kota K, et al. In-vitro antibacterial susceptibility of bacteria taken from infected root dentine to a mixture of ciprofloxacin, metronidazole and minocycline. Int Endod J. 1996;29:125-30.

13. Evans M, Davies JK, Sundqvist G, Figdor D. Mechanisms involved in the resistance of Enterococcus faecalis to calcium hydroxide. Int Endod J 2002;35:221-8.

14. Kontakiotis EG, Tsatsoulis IN, Papanakou SI, Tzanetakis GN. Effect of $2 \%$ chlorhexidine gel mixed with calcium hydroxide as an intracanal medication on sealing ability of permanent root canal filling: A 6-month follow-up. J Endod 2008;34:866-70.

15. Tong Z, Zhang Y, Ling J, Ma J et al. (2014) An In Vitro Study on the Effects of Nisin on the Antibacterial Activities of 18 Antibiotics against Enterococcus faecalis.PLoS ONE 2014; 9:1-18

16. Hemadri M, Thakur S, Sajjan G. Nisin vs calcium hydroxide - Antimicrobial efficacy on Enterococcus faecalis - An invitro study. Int $\mathrm{J}$ Contemp Dent 2011;2:55-61
17. Bozdogan B, Esel D, Whitener C, Browne FA, Appelbaum PC. Antimicrobial susceptibility of a vancomycinresistant Staphylococcus aureus strain isolated at the Hershey medical center. J Antimicrob Chemother 2003;52:864-8.

18. Delgado RJ, Gasparoto TH, Sipert CR, Pinheiro CR, Moraes IG, Garcia RB, et al. Antimicrobial effects of calcium hydroxide and chlorhexidine on Enterococcus faecalis. J Endod 2010;36:1389-93.

19. Mohammadi Z, Abbott PV. The properties and applications of chlorhexidine in endodontics. Int Endod J 2009;42:288302.

20. Figdor D, Gulabivala K. Survival against the odds: Microbiology of root canals associated with post-treatment disease. Endod Top 2011;18:62-77.

21. Greenstein G, Berman C, Jaffi n R. Chlorhexidine an adjunct to periodontal therapy. J Periodontol 1986;57:370-6.

22. Janaina Corazza Montero et al. Asessment of ion diffusion from a calcium hydroxidepropolis paste through dentin. Braz Oral Res (São Paulo) 2012 Jul-Aug;26(4):31822

23. Vahdaty A, Pi $\square$ ford TR, Wilson RF. Effi cacy of chlorhexidine in disinfecting dentinal tubules in vitro. Endod Dent Traumatol 1993;9:243-8.

24. Evans M, Davies JK, Sundqvist G, Figdor D. Mechanisms involved in the resistance of Enterococcus faecalis to calcium hydroxide. Int Endod J 2002;35:221-8.

25. Kuipers OP, Rollema HS, Yap WMGJ, Boot HJ, Siezen RJ, de Vos WM. Engineering dehydrated amino acid residues in the antimicrobial peptide Nisin. Journal of Biological Chemistry 1992; 267, 24: 340-346.

26. Bose R, Nummikoski P, Hargreaves K. A retrospective evaluation of radiographic outcomes in immature teeth with necrotic 
root canal systems treated with regenerative endodontic procedures. J Endod. 2009;35:1343-9.

27. Jack RW, Tagg JR, Ray B. Bacteriocins of Grampositive bacteria. Microbiological Reviews 1995; 59:171-200.

28. Hurst A. function of Nisin and Nisin like basic proteins in the growth cycle of streptococcus lactis. Nature 1967; 214:1232-1234.

29. Lin S, Zukerman O, Weiss EI, Mazor Y, Fuss Z. Antibacterial efficacy of a new chlorhexidine device to disinfect dentinal tubules. J Endod 2003; 29(6): 416-418.

30. Komorowski R, Grad H, Wu XY, Friedman S. Antimicrobial substantivity of chlorhexidine treated bovine root dentin. J Endod 2000 Jun;26(6):315-317.

31. Lage Marques JLS, Conti R, Antoniazzi JH, Guth I. Avaliação da velocidade de dissociação iônica do hidróxido de cálcio associado a diferentes veículos/ In vitro assessment of the ionic dissociation velocity of clcium hydroxide to diferente vehicles. Rev odontol Univ São Paulo. 1994 Apr-Jun;8(2):81-7.

32. Williams JM, Trope M, Caplan DJ, Shugars DC. Detection and quantitation of E. faecalis by real-time PCR (qPCR), reverse transcription-PCR (RT-PCR), and cultivation during endodontic treatment. J Endod 2006 Aug;32(8):715-721.

33. Poggio C, Colombo M, Scribante A, Sforza D, Bianchi S. In vitro antibacterial activity of different endodontic irrigants. Dent Traumatol 2012 Jun;28(3):205-209.

34. Turk BT, Sen BH, Ozturk T. In vitro antimicrobial activity of calcium hydroxide mixed with different vehicles against Enterococcus faecalis and Candida albicans. Oral Surg Oral Med Oral Pathol Oral Radiol Endod 2009 Aug;108(2):297301.
35. Narayanan LL, Vaishnavi C. Endodontic microbiology. J Conserv Dent 2010 OctDec;13(4):233-239. 